\title{
A Psicologia Social Contemporânea: Principais Tendências e Perspectivas Nacionais e Internacionais
}

\author{
Maria Cristina Ferreira ${ }^{1}$ \\ Universidade Salgado de Oliveira
}

\begin{abstract}
RESUMO - O presente trabalho faz um balanço do estado atual da Psicologia Social, no plano nacional e internacional. Para tanto, faz uma revisão inicial das principais tendências que marcaram a evolução da Psicologia Social na América do Norte, para, em seguida, apresentar as características atuais mais relevantes dessa disciplina na América do Norte, na Europa e na América Latina. Em seguida, detém-se na análise da recente produção brasileira em Psicologia Social. À guisa de conclusão, discute os desafios futuros que se colocam à produção nacional na área de Psicologia Social, especialmente no que diz respeito a seu impacto no cenário acadêmico internacional.
\end{abstract}

Palavras-chave: Psicologia Social; Psicologia Social Psicológica; Psicologia Social Sociológica; Psicologia Social Crítica.

\section{Contemporary Social Psychology: National and International Main Trends and Perspectives}

\begin{abstract}
This paper revises the current state of the art of Social Psychology in Brazil and abroad. For such, it initially reviews the main trends that influenced the evolution of North American Social Psychology, and presents the most relevant current characteristics of the discipline in North America, Europe and Latin America. Then, an analysis of the recent Brazilian publications in Social Psychology is offered. In conclusion, it discusses the future challenges of Brazilian scientific production in the area of Social Psychology, especially with respect to its impact on the international academic scenario.
\end{abstract}

Keywords: Social Psychology; Psychological Social Psychology; Sociological Social Psychology; Critical Social Psychology.

No decorrer de sua breve história, a Psicologia Social tem se caracterizado pela pluralidade e multiplicidade de abordagens teóricas adotadas como referenciais legítimos à produção de conhecimentos sociopsicológicos. Tal contexto tem dificultado sobremaneira a delimitação do objeto de estudo ou mesmo dos vários objetos de estudo dessa disciplina. Contudo, o binômio indivíduo-sociedade, isto é, o estudo das relações que os indivíduos mantêm entre si e com a sua sociedade ou cultura, sempre esteve no centro das preocupações dos psicólogos sociais, com o pêndulo oscilando ora para um lado, ora para o outro.

Assim é que, em seus primórdios, a Psicologia Social adotou uma abordagem eminentemente molar, dedicandose prioritariamente ao estudo dos processos socioculturais e concebendo o indivíduo como integrante desse sistema. Com o passar do tempo, porém, ela foi progressivamente adotando níveis mais moleculares de análise e se tornando mais individualista, ao se focalizar cada vez mais na investigação de processos intraindividuais. Em reação a tal individualização, a Psicologia Social irá assistir a outras mudanças de rumo, responsáveis pelo desenvolvimento de abordagens que se voltam novamente para a análise de eventos e processos histórica e culturalmente situados e dinâmicos.

A ênfase maior dada ao indivíduo ou à sociedade fez com que diferentes autores (House, 1977; Stephan \& Ste-

1 Endereço para correspondência: Rua Marquês de Valença, 80 Apto. 602. Rio de Janeiro, RJ. CEP 20550-030.E-mail: mcris@centroin. com.br. phan, 1985) começassem a defender a existência de duas modalidades de Psicologia Social: a Psicologia Social Psicológica e a Psicologia Social Sociológica. A Psicologia Social Psicológica, segundo a definição de G. Allport (1954), que se tornou clássica, procura explicar os sentimentos, pensamentos e comportamentos do indivíduo na presença real ou imaginada de outras pessoas. Já a Psicologia Social Sociológica, segundo Stephan e Stephan (1985), tem como foco o estudo da experiência social que o indivíduo adquire a partir de sua participação nos diferentes grupos sociais com os quais convive. Em outras palavras, os psicólogos sociais da primeira vertente tendem a enfatizar principalmente os processos intraindividuais responsáveis pelo modo pelo qual os indivíduos respondem aos estímulos sociais, enquanto os últimos tendem a privilegiar os fenômenos que emergem dos diferentes grupos e sociedades.

Para além dessa já hoje clássica divisão, a Psicologia Social desdobrou-se, mais recentemente, em outra vertente, qual seja a Psicologia Social Crítica (Álvaro \& Garrido, 2006) ou Psicologia Social Histórico-Crítica (Mancebo \& Jacó-Vilela, 2004), expressões que abarcam, na realidade, diferentes posturas teóricas. Assim é que, de acordo com Hepburn (2003), tanto o Socioconstrucionismo (Gergen, 1997) e a Psicologia Discursiva (Potter \& Wetherell, 1987), como a Psicologia Marxista, o pós-modernismo e o feminismo, entre outros, contribuem atualmente para o campo da Psicologia Social Crítica. Tais perspectivas guardam em comum o fato de adotarem uma postura crítica em relação às instituições, organizações e práticas da sociedade atual, bem 
como do conhecimento até então produzido pela Psicologia Social a esse respeito. Nesse sentido, colocam-se contra a opressão e a exploração presentes na maioria das sociedades e têm como um de seus principais objetivos a promoção da mudança social como forma de garantir o bem-estar do ser humano (Hepburn, 2003).

A evolução da Psicologia Social, nas diferentes partes de mundo, vem ocorrendo, de certa forma, associada às várias modalidades ou vertentes da disciplina. Assim é que, na América do Norte, e mais especialmente nos Estados Unidos da América, a Psicologia Social Psicológica foi e continua sendo a tendência predominante. Já na Europa, é possível se notar uma preocupação maior com os processos grupais e socioculturais, que sempre estiveram na base das preocupações da Psicologia Social Sociológica. Por outro lado, na América Latina, verifica-se a adoção da Psicologia Social Crítica como abordagem preferencial à análise dos graves problemas sociais que costumam assolar a região.

O objetivo do presente trabalho é fazer um breve balanço do estado atual da Psicologia Social, no plano nacional e internacional. Para tanto, inicia-se com uma breve revisão das principais tendências teóricas e temáticas que marcaram a evolução da Psicologia Social na América do Norte, para, em seguida, discutir as características mais relevantes da disciplina na atualidade, no contexto norte-americano, europeu e latino-americano. Posteriormente, detém-se na análise da recente produção brasileira em Psicologia Social, procurando compará-la com as tendências anteriormente apontadas. À guisa de conclusão, discute os desafios futuros que se colocam à produção nacional dessa área de conhecimento, especialmente no que diz respeito à sua visibilidade e impacto no cenário acadêmico internacional.

\section{A Psicologia Social na América do Norte: Evolução Teórica e Temática}

Duas obras, publicadas no ano de 1908, irão marcar a fundação oficial da Psicologia Social moderna na América do Norte: o livro Uma introdução à psicologia social, de autoria de William McDougall, e o livro Psicologia social: uma resenha e um livro texto, de autoria de Edward Ross (Pepitone, 1981). Contudo, Ross era sociólogo e McDougall, psicólogo, o que fez com que uma das obras se situasse no âmbito da Sociologia e outra, no escopo da Psicologia, anunciando, já naquela época, a separação ocorrida muito mais tarde entre a Psicologia Social Psicológica e a Psicologia Social Sociológica. Assim é que, durante algum tempo, na América do Norte, a Psicologia Social desenvolveu-se paralelamente no contexto de ambas as disciplinas. Logo, porém, isto é, ainda nas primeiras décadas do século XX, a Psicologia Social Psicológica estabelece-se como a tendência predominante no cenário norte-americano, em especial nos Estados Unidos da América (EUA), sob forte influência do behaviorismo.

Exemplo marcante de tal enfoque é o livro texto de Psicologia Social publicado em 1924, por Floyd Allport, considerado um dos mais famosos psicólogos sociais behavioristas da época. Ao defender que a Psicologia Social deveria concentrar-se no estudo experimental do indivíduo, na medida em que o grupo constituía-se tão somente em mais um estímulo do ambiente social a que esse indivíduo era submetido, Allport define os contornos da Psicologia Social Psicológica como uma disciplina objetiva, de base experimental e focada no indivíduo (Franzoi, 2007).

Os anos de 1920 e 1930 serão dominados pelo estudo das atitudes, da influência social interpessoal e da dinâmica de grupos. No que tange às atitudes, a investigação concentrouse no desenvolvimento de diferentes técnicas destinadas a mensurar tal constructo tomado como um fenômeno mental (McGarty \& Haslam, 1997). No que se refere à influência social e dinâmica de grupos, merecem destaque os experimentos realizados por Muzar Sheriff e Kurt Lewin, psicólogos europeus que imigraram para os EUA e receberam fortes influências do gestaltismo. Sheriff (1936) estava interessado no processo de formação de normas sociais, tendo chegado à conclusão de que os grupos desenvolvem normas que governam os julgamentos dos indivíduos que dele fazem parte, bem como dos novos membros que a elas também se adaptam, em função das normas grupais existirem à revelia de seus membros individuais.

Lewin e seus colegas (Lewin, Lippitt \& White, 1939) dedicaram-se à análise da influência dos estilos de liderança e do clima grupal sobre o comportamento dos membros do grupo, tendo observado que o estilo de liderança democrático produzia normas grupais construtivas e independentes, que levavam à realização de um trabalho produtivo, independentemente da presença ou não do líder. Já a liderança laissezfaire deixava os membros passivos, enquanto os grupos com liderança autocrática tornavam-se agressivos ou apáticos.

Dois principais temas marcaram as duas décadas subsequentes, que assinalam o período da Segunda Grande Guerra e do pós-guerra: atitudes e percepção de pessoa. A investigação das atitudes, iniciada nos anos 20 , prosseguiu nas décadas seguintes com os experimentos de Carl Hovland e sua equipe sobre comunicação e persuasão (Hovland, Janis \& Kelley, 1953), que levaram a importantes conclusões acerca dos diferentes fatores que interferiam na mudança de atitudes (Goethals, 2003). Tais estudos, bem como os que lhes sucederam, conferiram às atitudes um papel fundamental no campo da Psicologia Social Psicológica, tendo levado alguns autores (e.g., McGuire, 1968) a afirmar que tal fenômeno constituía-se em conceito central à Psicologia Social.

A investigação sobre percepção de pessoas, que até hoje consiste em uma das áreas centrais de estudo da Psicologia Social Psicológica, inicia-se com os trabalhos de Fritz Heider (1944, 1946, 1958), que também imigrou da Alemanha para os EUA durante a Segunda Grande Guerra, e recebeu forte influência do gestaltismo. Na publicação de 1944, o autor realiza o primeiro tratamento sistemático dos processos atribuicionais (Goethals, 2003), ao lançar o argumento de que os indivíduos associam as ações das pessoas a motivos e disposições internas, em função de perceberem uma justaposição ou gestalt entre o modo pelo qual as pessoas se comportam e a natureza de suas qualidades pessoais. Tal argumento sobre como as pessoas realizam atribuições causais será aprofundado no livro de 1958, traduzido para o português com o nome de "Psicologia das Relações Interpessoais". No artigo de 1946, Heider desenvolve a teoria do equilíbrio, segundo a qual as pessoas tendem a manter sentimentos e cognições 
coerentes sobre um mesmo objeto ou pessoa, de modo a obter uma situação de equilíbrio. Quando esse equilíbrio se desfaz, elas vivenciam uma situação de tensão e procuram restabelecê-lo, mediante a mudança de algum dos elementos da situação. Tal princípio encontra-se na base das teorias da consistência cognitiva que irão proliferar nos anos seguintes.

Ainda na área de percepção de pessoas, merecem destaque os estudos de Solomon Asch (1946), que irá aplicar os princípios gestaltistas em seus experimentos sobre a formação de impressões. Seus resultados levam-no a concluir que as informações sobre as características pessoais do outro são organizadas em um todo coerente, que difere da soma das partes e pode ser modificado por peças críticas de informação que provocam a reorganização desse todo. Ademais, a ordem com que as informações são recebidas afeta a formação da impressão global.

Os anos de 1950 e 1960 assistem à renovação do interesse pelas pesquisas sobre influência social e processos intergrupais, conduzidas, sobretudo, sob a liderança de Asch e Leon Festinger. Asch (1952), na esteira dos trabalhos anteriores de Sheriff (1936) sobre formação de normas sociais, já citados, interessa-se pela análise dos processos que levam os indivíduos a se conformarem com as normas do grupo ao realizarem julgamentos, ainda quando se torna evidente que tais julgamentos estão incorretos. Seus estudos sobre conformidade suscitaram uma série de desdobramentos posteriores, relacionados à investigação dos diferentes fatores que influenciavam tal fenômeno, além de inspirarem os experimentos clássicos de Milgram (1965), sobre obediência à autoridade.

Festinger (1954), sob a influência das investigações realizadas por Lewin, propõe a teoria dos processos de comparação social, na qual defende que as pessoas necessitam avaliar suas habilidades e opiniões a partir de comparações realizadas com outros indivíduos que lhes são similares. A referida teoria suscitou uma série de experimentos, reemergiu algumas vezes ao longo dos anos 70 e encontra-se solidamente estabelecida no momento atual, sendo usada, de forma recorrente, como mecanismo explanatório dos processos de formação da identidade pessoal e social (Goethals, 2003). Posteriormente, Festinger (1957) introduz a teoria da dissonância cognitiva, na qual estabelece que as pessoas são motivadas a procurar o equilíbrio entre suas atitudes e ações. Nesse sentido, quando instadas a mudar seu comportamento, mostram-se propensas a modificar também suas atitudes, de modo a restabelecerem o equilíbrio entre ações e atitudes. Apesar de ter sido alvo de críticas, a referida teoria foi uma das principais responsáveis pelo desenvolvimento da Psicologia Social Psicológica nas décadas seguintes (Rodrigues, Assmar \& Jablonski, 2000), tendo propiciado um grande número de pesquisas experimentais rigorosas, conduzidas com a finalidade de testar seus vários pressupostos.

As teorias da atribuição irão dominar o cenário sociopsicológico norte-americano a partir do final dos anos de $1960 \mathrm{e}$ durante os anos de 1970 e 1980, numa evidência da ascensão progressiva do cognitivismo no campo da Psicologia Social Psicológica. Apoiando-se nos pressupostos sobre as relações interpessoais antecipados por Heider $(1944,1958)$, as referidas teorias e seus desdobramentos (Jones \& Davis, 1965; Kelley, 1967; Ross, 1977; Weiner, 1986) vão se debruçar sobre os processos cognitivos responsáveis pelos julgamentos sociais, isto é, pelos mecanismos que levam o indivíduo a perceber e atribuir causas internas (pessoais) ou externas (situacionais) ao comportamento do outro, bem como sobre os erros e vieses que interferem em tais processos. As investigações desenvolvidas no âmbito das teorias atribuicionais contribuíram não apenas para a elucidação de alguns dos princípios que governam o pensamento social, mas também para a maior compreensão de outros fenômenos psicossociais, como, por exemplo, a depressão e o ajustamento conjugal (Goethals, 2003).

A partir dos anos 1980, o cognitivismo se consolida de vez como a perspectiva dominante na Psicologia Social Psicológica e no cenário norte-americano. Em consequência, o principal tema de investigação passa a ser a cognição social, que tem como objetivo básico compreender os processos cognitivos que se encontram subjacentes ao pensamento social (Fiske \& Taylor, 1984). Adotando tal perspectiva, os psicólogos sociais cognitivistas se dedicam então a fazer uma reanálise de temas que já vinham sendo estudados há algum tempo, procurando agora, porém, desvelar os mecanismos cognitivos subjacentes a tais fenômenos, tendência que se mantém até os dias atuais, conforme será visto mais à frente.

\section{A Crise da Psicologia Social na América do Norte}

A breve descrição da evolução teórica e temática da Psicologia Social norte-americana evidencia que, com o passar do tempo, o modelo de pesquisa-ação orientado para a comunidade e para o estudo dos grupos, introduzido por Lewin ainda nos anos de 1930, foi sendo paulatinamente abandonado e substituído pela investigação de fenômenos e processos eminentemente intraindividuais, de natureza cognitiva. Tendo como meta última a investigação das leis universais capazes de explicar o comportamento social, a Psicologia Social Psicológica estrutura-se progressivamente como uma ciência natural e empírica, que desconsidera o papel que as estruturas sociais e os sistemas culturais exercem sobre os indivíduos (Pepitone, 1981).

É nesse contexto que os anos de 1970 irão assistir ao surgimento da chamada "crise da Psicologia Social", motivada pela excessiva individualização da Psicologia Social Psicológica e dos movimentos sociais ocorridos nos anos de 1970 (como o feminismo, por exemplo). Nesse sentido, a crise da Psicologia Social se caracterizou, sobretudo, pelo questionamento das bases conceituais e metodológicas da Psicologia Social Psicológica até então dominante, no que tange à sua validade, relevância e capacidade de generalização (Apfelbaum, 1992).

Os questionamentos se dirigiam principalmente à sua relevância social, isto é, ao fato dessa vertente da Psicologia Social usar uma linguagem científica cada vez mais neutra e afastada dos problemas sociais reais e, consequentemente, desenvolver modelos e teorias que não eram capazes de contribuir para a explicação da nova realidade social que surgia. Adicionalmente, criticava-se a artificialidade dos experimentos conduzidos em laboratório, a falta de compromisso ético de seus mentores e a excessiva fragmentação dos modelos teóricos (Jones, 1985). 
As críticas referidas suscitaram grande resistência da comunidade científica estabelecida à época. No entanto, contribuíram para o movimento de internacionalização da Psicologia Social, responsável pelo desenvolvimento de uma Psicologia Social Européia, mais preocupada com o contexto social, e, mais recentemente, de uma Psicologia LatinoAmericana, voltada prioritariamente para os problemas sociais, a serem abordadas logo após uma breve revisão do atual estado da arte da Psicologia Social na América do Norte.

\section{A Psicologia Social na América do Norte: Tendências Atuais}

$\mathrm{Na}$ atualidade, os psicólogos sociais da América do Norte continuam se debruçando sobre temas tradicionais, que já tinham sido objeto de interesse dos que construíram a história da disciplina naquele país, mas também vêm se dedicando a novas temáticas que contribuíram para expandir e diversificar o espectro de fenômenos sociais investigados no contexto norte-americano. De acordo com Ross, Lepper e Ward (2010), em capítulo publicado na quinta e mais recente edição do Handbook of Social Psychology, três tópicos podem ser considerados centrais à psicologia social, em função do continuado interesse que vêm despertando, razão pela qual que se encontram presentes na maioria dos livros textos e palestras sobre o assunto. São eles a cognição social, as atitudes e os processos grupais. A esses tópicos, Ross e cols. ainda acrescentam algumas novas vertentes da Psicologia Social que, mais recentemente, vêm também se mostrando promissoras. Entre elas, merecem destaque a Neurociência Social e a Psicologia Social Evolucionista. Uma revisão dos principais desenvolvimentos conceituais e empíricos desses tópicos e vertentes será, então, realizada a seguir, como forma de situar o atual estado da arte da Psicologia Social norte-americana.

\section{Cognição social}

Segundo Carlston (2010), a cognição social pode ser vista atualmente como uma subárea da Psicologia, responsável por integrar uma série de micro-teorias que, ao longo do tempo, foram se desenvolvendo no contexto da Psicologia Social para explicar os modos pelos quais as pessoas pensam sobre si mesmas e sobre as coisas, formam impressões acerca de outras pessoas ou grupos sociais e explicam comportamentos e eventos. Apoiada no modelo de processamento de informação (que considera a atenção e percepção, a memória e o julgamento como diferentes etapas do processamento cognitivo), a cognição social dedica-se, assim, a estudar o conteúdo das representações mentais e os mecanismos que se encontram subjacentes ao processamento da informação social. Ela se focaliza, portanto, nos modos pelos quais as impressões, crenças e cognições sobre os estímulos sociais (o próprio indivíduo, bem como outras pessoas, grupos e eventos sociais) são formadas e afetam o comportamento.

No que tange ao conteúdo das representações mentais, a premissa básica é a de que as informações sociais são representadas cognitivamente sob a forma de estruturas mentais, isto é, de estruturas gerais de conhecimento, construídas, organizadas e estocadas na memória em categorias, com base nas informações obtidas no contato do indivíduo com seu mundo social (Quinn, Macrae \& Bodenhausen, 2003). Essas estruturas são denominadas de esquemas sociais, que podem tomar a forma de protótipos (representam os membros mais típicos) ou de exemplares (representam membros individuais), a serem acessados quando necessário.

Tal acesso ocorre por meio do processamento da informação social, mediante o qual o percebedor social identifica inicialmente os atributos salientes na pessoa alvo de sua percepção (Quinn \& cols., 2003). Em seguida, ele procura na memória as representações mentais ou esquemas similares aos atributos identificados, seleciona o mais apropriado e usa-o para realizar inferências acerca daquela pessoa, armazenando na memória de longo prazo a avaliação daí resultante.

Subjacente a todo esse processo, há o pressuposto básico de que as pessoas são limitadas em sua capacidade de processar informações e, por essa razão, utilizam-se de certas estratégias ou heurísticas para lidar com o grande volume e complexidade de informações sociais a que são submetidas em seu dia-a-dia (Pennington, 2000). Com isso, acabam por cometer erros e distorções em seus julgamentos e tomadas de decisão.

Algumas questões chaves têm permeado as investigações na área da cognição social (Quinn \& cols., 2003). Elas dizem respeito principalmente ao grau em que o processamento cognitivo é automático ou controlado, à influência da motivação e do afeto na cognição social e ao fato de a cognição ser abstrata ou situada.

No que diz respeito à automaticidade ou não do processamento da informação social, os resultados têm apontado que as pessoas podem realizar tanto julgamentos mais espontâneos e automáticos, quanto julgamentos mais conscientes e reflexivos, sendo que o uso de um tipo ou outro irá depender principalmente de sua motivação e habilidade em cada situação (Pennington, 2000). Nesse sentido, muitos dos julgamentos sociais ocorrem de forma inconsciente, não intencional, não controlável e demandam pouco da já limitada capacidade humana de processamento. Contudo, fenômenos mais complexos podem exigir um processamento mais consciente e controlado, o que irá depender da habilidade cognitiva do percebedor e/ou do fato de o processamento automático mostrar-se contrário a seus objetivos e metas.

$\mathrm{O}$ debate acerca das influências da motivação e do afeto na cognição social tem permeado essa área de estudos desde seus primórdios. Em que pese o fato de os primeiros psicólogos sociais cognitivistas terem rejeitado tais influências, as pesquisas mais recentes apontam que os afetos e motivações individuais interagem com as cognições na determinação do comportamento social (Schwarz, 1998). Nesse sentido, fatores motivacionais podem interferir no grau de esforço cognitivo despendido no processamento da informação social, bem como direcionar tal processamento, ao facilitar a ativação de esquemas relevantes às metas do indivíduo (Quinn \& cols., 2003). Por outro lado, tem-se também verificado que a codificação, elaboração e julgamento sociais são mediados pelas emoções, na medida em que elas contribuem para a ativação de informações com elas congruentes, além de provocarem reorganizações mentais que se mostrem mais 
consistentes com as experiências afetivas individuais (Quinn $\&$ cols., 2003).

As investigações iniciais na área da cognição social dedicaram-se, sobretudo, a esclarecer as diferentes características associadas à representação e processamento da informação social, ou seja, seu principal foco era uma cognição social abstrata e vinculada ao que se passava no interior da cabeça do indivíduo. Mais recentemente, porém, os psicólogos sociais cognitivistas passaram a explorar as características da situação social que interferem nas estratégias de processamento, ou seja, uma cognição social situada. Com isso, a ênfase se desloca do "pensamento sobre os estímulos sociais" para o "pensamento no contexto social" (Schwarz, 1998). Os resultados iniciais de tais estudos já puseram em evidência que os julgamentos sociais de uma mesma pessoa alvo podem diferir em função dos diferentes indivíduos que realizam tais julgamentos, a depender da natureza das interações de cada um com a pessoa alvo. Desse modo, um conjunto de pessoas interagindo ativamente e compartilhando suas avaliações, transmitirão informações que serão interpretadas e integradas diferentemente por cada percebedor (Smith \& Collins, 2009).

Entre os principais fenômenos psicossocias investigados atualmente, na perspectiva da cognição social, encontram-se o self, a formação de impressões, a percepção de pessoas e os estereótipos. No contexto do cognitivismo, o selfé conceituado como um autoesquema, isto é, como uma representação mental que contém o conhecimento do percebedor acerca de si próprio, no que se refere a suas características de personalidade, papéis sociais, experiências passadas e metas futuras (Quinn \& cols., 2003). As pesquisas sobre essa temática têm demonstrado que as pessoas diferem em termos dos atributos que consideram centrais à sua autodefinição, das dimensões distintas de seus autoesquemas que podem ser ativadas em situações diversas, das informações relativas a seu autoconceito que são processadas de modo mais completo e que são mais facilmente relembradas, e da forma com que a autodefinição do indivíduo afeta as crenças e expectativas que ele traz para uma determinada situação social. O self decorre, portanto, de um processo flexível e construtivo de julgamento sobre si mesmo, que leva o indivíduo a se apresentar de diferentes maneiras, a depender do ambiente social em que se encontra inserido, o que irá contribuir para sua adaptação a esse ambiente (Quinn \& cols., 2003).

Os estereótipos, a formação de impressões e a percepção de pessoas constituem temas tradicionalmente estudados pela Psicologia Social e centrais à área de cognição social. Em contraste com os autoesquemas, que contêm as estruturas de conhecimento sobre o próprio indivíduo, os estereótipos consistem em esquemas ou representações mentais sobre grupos sociais. Nesse sentido, eles interferem ativamente no processo de formação de impressão e percepção de pessoas, que é o responsável pela integração de informações e avaliação de outros indivíduos, ou seja, pelas formas com que o percebedor interpreta os indivíduos que o rodeiam. Os achados empíricos mais recentes nesse campo de estudos têm demonstrado que as pessoas costumam realizar inferências iniciais (formação e percepção de pessoa) baseadas em estereótipos, o que significa dizer que essas categorias sociais são ativadas de modo automático ou inconsciente, tão logo o percebedor identifica um determinado indivíduo como pertencente a certo grupo social. Posteriormente, dependendo de sua motivação e habilidade, poderá corrigir essa impressão inicial, com base em informações mais individualizadas e que se mostrem congruentes ou incongruentes com seus estereótipos (Quinn \& cols., 2003).

Em síntese, a investigação atual na área da cognição social evoluiu progressivamente, de modo a incluir temas não abordados inicialmente, como a automaticidade dos processos sociocognitivos, os afetos e a motivação. Tais avanços contribuíram sobremaneira para ampliar o escopo da teorização e pesquisa nesse campo de estudos, além de alargarem a compreensão da ampla gama de fenômenos responsáveis pela atuação do indivíduo em seu contexto social.

\section{Atitudes}

As atitudes constituem-se em um dos construtos mais antigos no contexto sociopsicológico, embora suas definições nem sempre sejam consensuais. Contudo, alguns temas são recorrentes nas várias definições oferecidas pelos autores, como o fato de elas se encontrarem associadas a diversas manifestações, incluindo-se as crenças, os valores e as opiniões, e de elas envolverem avaliações de objetos sociais (Saucier, 2000). De acordo com Fabrigar e Wegener (2010), as atitudes podem ser conceituadas como avaliações gerais e duradouras, que variam de um extremo positivo a um extremo negativo, dos objetos presentes no mundo social, o que abrange pessoas, grupos, comportamentos etc. Nesse sentido, elas integram as cognições e afetos sobre tais objetos (Crano \& Prislin, 2006).

A partir de um interesse inicial pelo desenvolvimento de técnicas destinadas a mensurar as atitudes, as investigações nessa área evoluíram paulatinamente na busca de modelos mais sofisticados e capazes de explicar os processos psicológicos responsáveis pela formação e mudança de atitudes, bem como pela consistência entre atitudes e comportamento. Embora as expressões "formação de atitudes" e "mudança de atitudes" sejam frequentemente usadas em conjunto (formação e mudança de atiudades), elas se encontram, na realidade, vinculadas a processos distintos (Crano \& Prislin, 2006). Assim é que a formação de atitudes costuma ocorrer de forma não consciente, por meio de aprendizagem condicionada ou mediante a mera exposição a estímulos vivenciados como afetivamente positivos.

A mudança de atitudes, por seu turno, costuma ocorrer no plano consciente e vem sendo mais recentemente explicada pelos modelos de processos duais (Chaiken \& Trope, 1999), que atualmente dominam a pesquisa na área de persuasão. Tais modelos sustentam que quando os percebedores são competentes e encontram-se adequadamente motivados, eles costumam se engajar em um processo de análise sistemática das mensagens persuasivas. Se elas contiverem argumentos consistentes, isto é, apoiados na realidade e estruturados de maneira lógica e racional, serão capazes de gerar mudanças atitudinais apoiadas em tais argumentos, as quais se mostrarão duradouras e resistentes a mudanças. Caso, porém, os percebedores estejam desmotivados ou não tenham suficiente habilidade para adequadamente processar as mensagens, eles irão se apoiar em indícios periféricos e mais facilmente accessíveis (da fonte, da mensagem ou da situação) ou em 
heurísticas para processar as mensagens. Assim, por exemplo, eles podem usar como heurística a regra do consenso e, simplesmente, concordar com a maioria. Tais mudanças atitudinais serão, porém, menos estáveis e resistentes à mudança. Em síntese, os modelos duais sustentam que a fonte e a mensagem possuem funções distintas e interagem com a motivação e a habilidade na configuração do processo de mudança de atitudes (Crano \& Prislin, 2006), isto é, que tal processo depende da motivação e habilidade dos indivíduos para processar informações relevantes à mudança.

No que tange à consistência entre atitudes e comportamento, os achados mais recentes têm evidenciado que determinadas propriedades estruturais das atitudes são responsáveis pela maior ou menor capacidade de as atitudes preverem o comportamento (Fabrigar \& Wegener, 2010). Assim, por exemplo, tem-se verificado que maior consistência entre julgamentos atitudinais e comportamento costuma emergir quando ambos os tipos de respostas se apoiam em inputs ou informações similares (Schwarz, 1998). Adicionalmente, evidências têm sido reunidas sobre o fato de que atitudes mais automáticas costumam predizer comportamentos mais espontâneos, ao passo que atitudes mais deliberadas costumam predizer comportamentos mais conscientes (Petty \& Briñol, 2010). Por outro lado, mudanças atitudinais apoiadas em processos lógicos, motivados e conscientes apresentam maior probabilidade de influenciar o comportamento (Crano \& Prislin, 2006).

Um desenvolvimento mais recente no campo das atitudes diz respeito ao uso de medidas implícitas para mensurá-las (Petty \& Briñol, 2010). Assim é que, após um longo período dominado pelos instrumentos de autorrelato com foco nas avaliações conscientes e deliberadas dos indivíduos (medidas explícitas) como técnica preferencial de mensuração das atitudes, os pesquisadores têm recorrido cada vez mais à adoção de medidas que captam as avaliações mais automáticas e não conscientes (medidas implícitas, como os testes de associações de palavras, por exemplo). Tais avanços têm contribuído sobremaneira para a elucidação das condições em que as atitudes são formadas e modificadas, bem como de suas ligações com o comportamento, conforme brevemente revisto nessa seção.

\section{Processos grupais}

O estudo dos fenômenos grupais tem uma longa história na área da Psicologia Social, tendo se constituído no objeto de preocupações de vários pioneiros da Psicologia norteamericana, como Lewin, Sheriff e Asch. Com o passar do tempo, porém, as investigações nessa área tenderam a se concentrar em níveis cada vez mais micros de análise, que se focalizavam sobremaneira nas qualidades, características e ações dos membros individuais, quando na presença de um grupo. Nesse sentido, pouca atenção foi dada durante algum tempo aos processos dinâmicos que levam o indivíduo a participar da vida grupal e aos efeitos da não participação, aos processos que levam o grupo a modificar o comportamento de seus membros e a agir como uma unidade autônoma e diferenciada de qualquer um de seus membros etc., especialmente no contexto norte-americano (Forsyth \& Burnette, 2010).
Mais recentemente, porém, avanços realizados em metodologias de análises de dados que consideram o grupo uma unidade autônoma e não uma soma de indivíduos têm propiciado avanços consideráveis no estado atual do conhecimento sobre os processos grupais. Nesse sentido, Moura, Leader, Pelletier e Abrams (2009), em levantamento recente sobre o estado da pesquisa sobre grupos, realizado em alguns dos periódicos norte-americanos e europeus mais citados na área de Psicologia Social, concluíram que um terço das publicações nesses periódicos continha pesquisas na área de processos grupais, o que evidencia o vigor que a referida temática continua tendo no contexto das investigações psicossociais.

\section{Neurociência social}

A área de Neurociência Social, assim cunhada pela primeira vez por Cacioppo e Berntson (1992), surge movida principalmente pelo interesse de investigar as possíveis associações existentes entre a cognição social e as funções cerebrais, com o intuito de compreender o papel desempenhado pelas estruturas neurais no processamento da informação social (Adolphs, 2009). O pressuposto básico é, portanto, o de que determinados mecanismos neurocerebrais são responsáveis pelo raciocínio social, isto é, que existem determinadas estruturas cerebrais especializadas nas atividades de autopercepção e percepção dos demais indivíduos e grupos sociais, bem como nas ações que permitem a vida em sociedade (Heatherton \& Wheatley, 2010). Em resumo, a Neurociência Social dedica-se à análise das bases neurobiológicas da cognição social.

$\mathrm{O}$ advento de novas técnicas de imagens neurais, em especial a ressonância magnética funcional, tem permitido a localização precisa de diferentes estruturas cerebrais e proporcionado consideráveis avanços à Neurociência Social, apesar de tal área ainda se encontrar na infância. Nesse sentido, evidências já disponíveis apontam que determinadas regiões do córtex cerebral superior são especializadas em determinados processos sociocognitivos, como, por exemplo, a percepção de si mesmo, a detecção e compreensão de faces, vozes e movimentos humanos, a percepção de sentimentos dos outros, a atribuição de estados mentais ao outro etc. (Grande-García, 2009). Por essa razão, lesões cerebrais nessas áreas podem afetar negativamente os julgamentos e interações sociais.

Assim, por exemplo, a meta-análise realizada por Overwalle (2009) reuniu evidências de que a percepção de estados mais temporários (metas, desejos e intenções) está relacionada à ativação da junção parietal temporal, enquanto a inferência de disposições mais duradouras ou de normas e eventos interpessoais encontra-se associada à ativação do córtex pré-frontal medial, ainda que alguns estados temporários possam também ativá-lo. Tais dados levaram o autor a concluir que esses dois substratos neurais vinculam-se particularmente à cognição social. Contudo, Adolphs (2009) adverte que cognição social também é sensível ao contexto, o que faz com que a interface entre cérebro e cognição social seja modulada pelo contexto social e pelo autocontrole volitivo. 
A Neurociência Social pode ser vista como um campo promissor de investigação na área de Psicologia Social que poderá indubitavelmente contribuir para maior compreensão do comportamento social. Para tanto, será, porém, necessário avançar em uma série de questões que até o momento ainda não foram suficientemente esclarecidas pelos estudos que vêm sendo conduzidos sob essa perspectiva. Assim é que a análise das inter-relações entre cérebro e comportamento social tem se limitado até aqui à consideração de processos intraindividuais e situacionais, o que lança dúvidas sobre a efetividade de tal abordagem para o estudo de fenômenos que se encontram na convergência de variáveis individuais e macrossociais, como, por exemplo, os processos intergrupais (Dovidio, Pearson \& Orr, 2008). De todo modo, ela poderá atuar como uma perspectiva complementar a outras mais apropriadas à investigação das influências macrossociais na conduta social.

\section{Psicologia social evolucionista}

A Psicologia Social Evolucionista tem suas origens na teoria da evolução genética de Darwin, segundo a qual a evolução das espécies se dá com base em um ciclo que inclui a variação, a competição e a hereditariedade. Desse modo, as espécies apresentam variações em suas características constituintes e habilidades para lidarem com seu meio ambiente. Como os recursos à vida dessas espécies que se encontram disponíveis no meio ambiente são escassos, somente aquelas dotadas de maiores habilidades competitivas irão conseguir sobreviver, bem como transmitir tais habilidades para a geração seguinte. Em gerações sucessivas, mudanças nas espécies acabam por ocorrer no sentido de acentuarem cada vez mais essas capacidades de sobrevivência (Mesoudi, 2009).

Apoiando-se em tais pressupostos, os psicólogos sociais evolucionistas defendem que processos similares à evolução genética operam na transmissão da cultura. Postula-se, assim, que os diferentes grupamentos humanos variam em suas crenças e valores culturais, e que, em função de recursos cognitivos limitados, algumas dessas variantes culturais são mais prováveis de serem aprendidas e lembradas, em geral aquelas transmitidas por modelos mais proeminentes (pais, celebridades etc.). Nesse sentido, a transmissão da cultura se dá por meio de processos de imitação e aprendizagem social, por meio dos quais ocorre a seleção natural dos valores a serem transmitidos à outra geração (Mesoudi, 2009).

De acordo com Maner e Kenrich (2010), a Psicologia Social Evolucionista não se opõe às tradicionais teorias da Psicologia Social, mas, ao contrário, procura explicar alguns resultados controversos obtidos em diferentes áreas psicossociais. Para tanto, apoia-se no pressuposto de que muitos pensamentos, sentimentos e comportamentos sociais encontram-se associados a mecanismos biológicos que interagem de forma dinâmica com processos psicológicos e de aprendizagem, no interior de uma determinada cultura. Nesse sentido, vários temas abordados pela Psicologia Social Psicológica têm sido re-examinados sob a perspectiva da Psicologia Social Evolucionista, como, por exemplo, as relações interpessoais e intergrupais, com resultados promissores que evidenciam a pertinência e propriedade de se utilizar tal abordagem de forma complementar, na investigação de determinados fenômenos psicossociais (Maner \& Kenrich, 2010; Mesoudi, 2009).

\section{A Psicologia Social na Europa: Evolução e Tendências Atuais}

Apesar de a Psicologia Social europeia ter inicialmente caminhado lado a lado com a Psicologia Social Psicológica, ela começou, a partir dos anos 1970 e motivada pela crise da Psicologia Social na América do Norte, a adquirir sua própria identidade e a demonstrar maior preocupação com a estrutura social. Desde então, ela vem crescendo progressivamente em tamanho e influência. Entre os temas de estudo mais frequentes no contexto europeu encontram-se a identidade social, que se insere principalmente no contexto das relações intergrupais, e as representações sociais, que remetem a uma psicologia dos grupos e coletividades. Tais temas serão revistos a seguir, como forma de contextualizar a Psicologia Social européia.

\section{Identidade social}

A teoria da identidade social surge na literatura sociopsicológica com Henri Tajfel, da Universidade de Bristol, na Inglaterra, e seus colaboradores (Tajfel, 1981; Tajfel \& Turner, 1986), que procuraram enfatizar a dimensão social do comportamento individual e grupal, ao postularem que o indivíduo é moldado pela sociedade e pela cultura. Nesse sentido, defendem que as relações intergrupais estão intimamente relacionadas a processos de identificação grupal e de comparação social.

A teoria da identidade social apoia-se em três postulados básicos: (1) o autoconceito é derivado da identificação e pertença grupal; (3) as pessoas são motivadas a manter uma autoestima positiva; (3) as pessoas estabelecem uma identidade social positiva mediante a comparação favorável de seu próprio grupo (in-group) com outros grupos sociais (out-groups). Nesse sentido, quando tal comparação não se mostra favorável ao próprio grupo, elas irão adotar diferentes estratégias para recuperar o favoritismo de seu próprio grupo, como forma de assegurar uma autoestima positiva.

As primeiras demonstrações sobre a identificação social e o favoritismo do próprio grupo foram realizadas por Tajfel (1981), mediante o uso de experimentos adotando a técnica do paradigma dos grupos mínimos, em que as pessoas eram arbitrariamente assinaladas a grupos com os quais não possuíam nenhuma identificação anterior e, mesmo assim, tendiam a manter a vantagem do próprio grupo. Desde então, o referido princípio tem sido objeto de inúmeras verificações empíricas, dentro e fora do laboratório. Tais estudos têm consistentemente apontado que a força da identificação com o próprio grupo e a necessidade de manter uma autoestima positiva encontram-se na base das relações intergupais, ao provocarem o favoritismo do próprio grupo e as atitudes discriminatórias daí decorrentes (Brown, 2000). Assim, por exemplo, a revisão de 34 estudos conduzida por Aberson, Healy e Romero (2000) observou que as pessoas de auto- 
estima elevada exibiam maior favoritismo ao próprio grupo do que as de autoestima mais baixa. Outros estudos têm verificado que as pessoas que vivenciam uma diminuição de sua autoestima tendem a expressar maior preconceito (Fein \& Spencer, 1997).

Um extensão da teoria da identidade social é a teoria da autocategorização de Turner, Hogg, Oakes, Reicher e Wetherell (1987). Seu foco são os fatores que levam os indivíduos a realizarem determinadas categorizações, bem como suas consequências para o comportamento coletivo. Postula-se, assim, que a depender da força da pressão social presente em determinadas situações, as pessoas deixarão de lado suas características idiossincráticas (autopercepção) e ativarão suas identidades sociais, o que as levará ao engajamento em ações coletivas. De acordo com esses autores, portanto, as identidades sociais consistem em categorias socialmente construídas que se mostram mais ou menos salientes, em função das características da situação social.

A teoria da identidade social, em suas múltiplas vertentes, pode ser vista, portanto, como uma abordagem que, nos últimos 30 anos, vem procurando elucidar o papel desempenhado pelo autoconceito nos processos e relações intergrupais, mediante a articulação de fenômenos de natureza sociocognitiva, motivacional e macrossocial que permeiam a vida coletiva. Inicialmente surgida na Europa, ela tem sido adotada cada vez mais como referencial por pesquisadores de diversas partes do mundo, incluindo-se aí muitos psicólogos norte-americanos, podendo ser considerada atualmente uma das mais significativas teorias para a análise das relações entre o indivíduo e o grupo (Hogg, 2006). Nesse sentido, ela vem sendo utilizada mais recentemente não apenas no estudo das relações intergrupais, mas também na investigação da autocategorização e de vários processos grupais, como a coesão, a liderança, a influência social etc. No entanto, ela continua sem resolver um de seus principais desafios, qual seja promover a maior compreensão dos aspectos afetivos que se encontram subjacentes às formas mais hostis e destrutivas de comportamento intergrupal (Brown, 2000).

\section{Representações sociais}

Segundo Moscovici (1981), as representações sociais englobam um conjunto de conceitos, imagens e explicações que se originam do senso comum, no contexto das interações e comunicações interpessoais. Nesse sentido, elas vão se modificando à medida que novos significados vão sendo acrescentados à realidade. Ainda de acordo com o autor (Moscovici, 1984), a função das representações sociais é dar sentido ao desconhecido, transformando o não familiar em algo familiar. Para tanto, apoia-se nos processos de ancoragem e objetivação. O primeiro se ocupa de inserir o fenômeno não familiar em uma rede de categorias e imagens familiares, de modo a que ele possa ser interpretado, enquanto o segundo tem por objetivo transformar o que é abstrato em algo concreto e que pode ser, assim, tocado.

Uma extensão do trabalho de Moscovici é a teoria do núcleo central, que foi proposta por Abric (1994) e defende que toda representação social organiza-se em torno de um núcleo central e de elementos periféricos. O núcleo central consiste no elemento essencial da representação, em função de organizá-la e lhe dar sentido. Ele é mais rígido e ancora-se na memória coletiva do grupo, em suas condições históricas e sociais. Já os elementos periféricos são mais móveis e flexíveis. Sua função é proteger a estabilidade do núcleo central e permitir a adaptação de grupos e indivíduos a situações específicas. O núcleo central é, portanto, normativo, enquanto os elementos periféricos são funcionais, por possibilitarem a ancoragem da representação na realidade do momento (Sá, 1996).

A teoria das representações sociais foi amplamente difundida nas décadas seguintes à sua introdução na literatura sociopsicológica, especialmente entre os psicólogos europeus e latino-americanos, com os pesquisadores de tal corrente procurando aplicar seus princípios teóricos a inúmeros eventos aos quais podem ser atribuídos significados que emergem do senso comum. Nesse sentido, a análise das teorias mantidas pelo homem comum tem contribuído para a compreensão de fenômenos tão diversificados quanto a saúde/doença, a doença mental, a violência, a justiça, o desemprego, a amizade, os sistemas tecnológicos, os sistemas econômicos etc.

\section{A Psicologia Social na América Latina: Evolução e Tendências Atuais}

A Psicologia Social praticada na América Latina, até a década de 1970, esteve grandemente influenciada pelo paradigma da Psicologia Social Psicológica, tendência até hoje dominante na América do Norte. Ao final da década, porém, muitos psicólogos sociais latino-americanos iniciaram um forte movimento de questionamento à Psicologia Social norte-americana (em função de seu experimentalismo e individualismo), em prol de uma psicologia social mais contextualizada, isto é, mais voltada para os problemas políticos e sociais que a região vinha enfrentando. Estimulados pela arbitrariedade dos regimes militares e pela grande desigualdade social do continente, esses psicólogos sociais irão defender uma ruptura radical com a psicologia social tradicional (Spink \& Spink, 2005).

Nesse sentido, vários psicólogos latino-americanos passaram a adotar como referencial de seus estudos a Psicologia Social Crítica. Um autor frequentemente citado como legítimo representante dessa perspectiva na Psicologia Social latino-americana é Martin-Baró, psicólogo e padre jesuíta espanhol, radicado em El Salvador, que defendia em suas obras o desenvolvimento de uma psicologia social comprometida com a realidade social latino-americana.

Como forma de ajudar a minorar a situação estrutural de injustiça social que permeia a maioria dos povos latino-americanos, Martín-Baró (1996) enfatiza que a principal tarefa do psicólogo social deve ser a conscientização de pessoas e grupos, como forma de levá-los a desenvolver um saber crítico sobre si e sobre sua realidade, que lhes permita controlar sua própria existência. De acordo com o autor, urge, portanto, que os psicólogos sociais contribuam para a construção de identidades pessoais, coletivas e históricas capazes de romper a situação de alienação das maiorias populares oprimidas e desumanizadas que vivem à margem da sociedade dominan- 
te e, consequentemente, levar à mudança social. Trata-se, assim, de desenvolver um saber psicológico historicamente construído que se mostre capaz de compreender e contribuir para sanar os problemas que atingem as maiorias populares e oprimidas. Para ele (Martin-Baró, 1989), então, a construção teórica em psicologia social deve emergir dos problemas e conflitos vivenciados pelo povo latino-americano, de forma contextualizada com sua história.

Outra autora de destaque no cenário latino-americano é Maritza Montero, da Venezuela. Em revisão recente sobre a Psicologia Social Crítica em seu país, Montero e Montenegro (2006) assinalam que ela se caracteriza principalmente por questionar os modos de produção de conhecimento e prática da Psicologia e perseguir a transformação social e a relevância social da pesquisa e intervenção sobre os problemas sociais que assolam o país. Para tanto, coloca-se contra as abordagens positivistas e experimentais, a neutralidade científica e as perspectivas individualistas de abordagem dos fenômenos psicossociais, defendendo, ao contrário, a produção de um conhecimento contextualizado, participante e coconstruído por pesquisadores e atores sociais, como forma de contribuir para a solução dos problemas sociais que vivenciam e transformar sua realidade social.

Apoiando-se primordialmente em tal referencial, os psicólogos venezuelanos, muitas vezes em colaboração com colegas latino-americanos de outras nacionalidades, têm direcionado suas investigações para as temáticas dos estereótipos, autoimagens, identidades sociais, nacionalismo, movimentos sociais, poder social, relações de gênero, violência doméstica, direitos reprodutivos da mulher, entre outros. Tais estudos têm sido acompanhados, também, por uma intensa produção teórica sobre os princípios paradigmáticos da Psicologia Comunitária, bem como suas práticas e inserção no campo da ciência, sobre os modos de construção do conhecimento, sobre o conceito de empoderamento, sobre a pesquisa participativa etc. (Montero \& Montenegro, 2006).

Iniciativas sob a perspectiva da Psicologia Crítica também têm despontado em outros países latino-americanos como, por exemplo, a Colômbia (Molina-Valencia \& Mesa, 2006), o Chile (Shafir, 2006) e o Brasil, que será objeto de análise mais detalhada na próxima seção. Cumpre registrar, porém, que a Psicologia Social Crítica não é a única tendência dominante na América Latina, na medida em que nela coexistem múltiplas tendências, havendo, assim, vários psicólogos sociais na região que vêm desenvolvendo seus trabalhos com o apoio de referenciais da Psicologia Social norte-americana ou da Psicologia Social europeia. Nesse sentido, Álvaro e Garrido (2006) questionam se é possível afirmar a existência de uma Psicologia Social latino-americana que reúna traços próprios de identidade.

\section{A Produção Brasileira em Psicologia Social}

As primeiras publicações brasileiras com foco na análise de questões psicossociais começaram a surgir na década de 1930 (Bonfim, 2003). No entanto, a institucionalização da Psicologia Social irá ocorrer apenas em 1962, quando o Conselho Federal de Psicologia, por meio do parecer 403/62, criou o currículo mínimo para os cursos de Psico- logia, estabelecendo, assim, a obrigatoriedade do ensino da Psicologia Social.

A partir de então, e até os anos 1970, a Psicologia Social Psicológica norte-americana foi a dominante, de modo semelhante ao que ocorreu no resto da América Latina. Uma das obras bastante adotada nos cursos de Psicologia Social durante esse período, e que expressa tal tendência, é o livro "Psicologia social", de autoria de Aroldo Rodrigues, publicado pela primeira vez em 1972 e que se encontra atualmente em sua $23^{\mathrm{a}}$ edição. Seu autor foi também o responsável pelo desenvolvimento de uma profícua linha de pesquisa em Psicologia Social no país, a qual foi divulgada em uma série de artigos publicados em periódicos nacionais e estrangeiros, ao longo dos anos 1970 e 1980.

No entanto, a partir do final da década de 1970, os psicólogos sociais brasileiros também irão participar ativamente do movimento de ruptura com a Psicologia Social tradicional ocorrido na América Latina. Assim é que, a partir da publicação, em 1984, do livro organizado por Silvia Lane e Vanderley Codo e intitulado "Psicologia social: O homem em movimento", vários outros manuais brasileiros de Psicologia Social (Campos \& Guareschi, 2000; Jacques, Strey, Bernardes, Guareschi, Carlos \& Fonseca, 1998; Lane \& Sawaia, 1994; Mancebo e Jacó-Vilela, 2004) se sucederam, na perspectiva da Psicologia Social Crítica. De acordo com Carvalho e Dunker (2006), tal movimento constitui atualmente uma das principais correntes da Psicologia brasileira, e vem procurando abordar, sobretudo, alguns dos problemas sociais enfrentados pelo país, como, por exemplo, a violência doméstica, as crianças de rua, a pobreza, a desigualdade social e a exclusão educacional.

Outro evento que marcou a evolução da Psicologia Social brasileira foi a criação, em 1980, da Associação Brasileira de Psicologia Social (ABRAPSO), estabelecida com o propósito de redefinir o campo da Psicologia Social e contribuir para a construção de um referencial teórico orientado pela concepção de que o ser humano constitui-se em um produto histórico-social, de que indivíduo e sociedade se implicam mutuamente (Jacques \& cols., 1998). A partir da década de 1980, começaram também a se desenvolver no país os cursos de pós-graduação stricto-sensu, que exerceram importante papel na estruturação de diferentes linhas de pesquisa na área de Psicologia Social, orientadas por paradigmas e tendências diversificadas, bem como no incremento da produção científica brasileira em Psicologia Social.

Com o intuito de obter um breve panorama da atual produção brasileira em Psicologia Social, que permitisse sua posterior contextualização no cenário internacional, foi realizado um levantamento de todos os volumes disponíveis na base de dados Scielo de seis periódicos nacionais da área de Psicologia, avaliados como A1 ou A2 no sistema QUALIS 2010, a saber: Estudos de Psicologia (Campinas); Estudos de Psicologia (Natal); Psicologia em Estudo; Psicologia e Sociedade; Psicologia: Reflexão e Crítica; Psicologia: Teoria e Pesquisa. Os volumes de 2010 não foram, porém, incluídos, em função de que alguns desses periódicos ainda não contavam com tais volumes disponibilizados eletronicamente por ocasião da consulta, realizada durante o mês de julho de 2010.

Todos os artigos publicados nesses periódicos, durante os períodos assinalados, foram examinados, excetuando-se 
as resenhas, notícias, entrevistas e editoriais. Desse total, foram selecionados, para posterior análise, os que podiam ser classificados como pertencentes à área de Psicologia Social. Cabe aqui mencionar as dificuldades encontradas no estabelecimento de critérios para a categorização dos artigos no escopo da Psicologia Social contemporânea, em função da pluralidade de formas que a disciplina vem progressivamente assumindo, o que torna por vezes os limites entre ela e alguns outros campos do saber psicológico muito tênues.

Nesse sentido, optou-se pelo exame individual de cada artigo e eleição dos que podiam ser identificados com pelo menos uma das três principais vertentes atuais da Psicologia Social, discutidas previamente (Psicologia Social Psicológica, Psicologia Social Sociológica e Psicologia Social Crítica). Assim, por exemplo, fenômenos psicossociais como papéis familiares, infância, juventude e envelhecimento, violência intrafamiliar, saúde mental e meio ambiente, que vêm sendo estudados não apenas pela Psicologia Social, mas também por outras áreas da Psicologia (Psicologia do Desenvolvimento, Psicologia da Saúde, Psicologia Clínica, Psicologia Ambiental, Psicologia do Trabalho etc.), foram incluídos apenas quando foi possível obter indicações de que eles estavam sendo abordados por meio de referenciais teóricos e/ou temas afetos a pelo menos uma das três vertentes sociopsicológicas supra mencionadas. Considerando-se, por outro lado, que o objetivo era fazer um levantamento da produção nacional, os artigos da área de Psicologia Social, cujos autores eram todos estrangeiros e/ou não incluíam indivíduos brasileiros como participantes, também foram excluídos da presente análise.

Adotando-se tais critérios, foram selecionados 636 artigos para compor uma base de dados com informações sobre características de autoria e sua natureza teórica, temática e metodológica. Na Tabela 1, apresenta-se a distribuição do número de periódicos e fascículos examinados ao longo do período estudado, bem como do número de artigos classificados como pertencentes à categoria de estudos em Psicologia Social, nos diferentes periódicos analisados.

Com relação ao número de autores, observou-se maior percentual de artigos com dois autores (41\%), seguido pelo percentual de artigos com um autor (24\%) ou com três autores (18\%), e com o restante (17\%) oscilando entre artigos de quatro a 13 autores. Entre os artigos com mais de um autor, a maioria $(76 \%)$ dizia respeito a parcerias entre autores de uma mesma instituição, seguida por parcerias interestaduais (14\%) ou internacionais $(10 \%)$. Tais dados podem ser vistos como um reflexo do incentivo à publicação de teses e dissertações em que os orientadores atuam como coautores dos trabalhos de seus orientandos.

No que tange à afiliação institucional desses autores, a maioria provinha de instituições públicas federais $(47 \%)$ ou estaduais (18\%), com somente $21 \%$ pertencendo a instituições privadas e o restante (14\%) referindo-se a autorias que combinavam duas ou mais dessas categorias. Já no que se refere à distribuição geográfica dos autores, destacou-se o predomínio da região sudeste (41\%), seguida pela região sul $(26 \%)$, nordeste $(16 \%)$ e centro-oeste $(9 \%)$, com a região norte aparecendo com menos de $1 \%$ e o restante $(8 \%)$ se referindo a parcerias inter-regionais. Tais dados vão ao encontro do fato de o maior número de centros de pós-graduação stricto-sensu em Psicologia do país concentrar-se nas regiões sudeste e sul que, contam, consequentemente, com maior contingente de pesquisadores, os quais, por sua vez, angariam a maior parte dos recursos dos órgãos de fomento para a pesquisa.

Atendo-se à vertente da Psicologia Social na qual os artigos se inseriam, foi possível constatar que a maior parte dos artigos identificava-se com os fundamentos teóricometodológicos da Psicologia Social Crítica (46\%), seguida pelo percentual de artigos identificados com a Psicologia Social Psicológica, de natureza predominantemente norteamericana (38\%), e com a Psicologia Social Sociológica, de base eminentemente europeia $(16 \%)$.

A preferência dos psicólogos brasileiros pela Psicologia Social Crítica mostra-se coerente com a tendência mais recente de adesão a tal perspectiva que vem sendo observada em diversos outros países da América Latina. Outrossim, cumpre enfatizar o importante papel que o periódico Psicologia e Sociedade vem desempenhando na veiculação da produção brasileira associada à Psicologia Social Crítica. Assim é que pouco mais da metade dos artigos inseridos nessa perspectiva (53\%) foram publicados no periódico em questão, com os demais se dividindo pelos outros cinco periódicos analisados.

Em relação às temáticas de estudo, observou-se que as que vêm despertando maior interesse dos psicólogos sociais brasileiros são as práticas sociais (15\%), as representações sociais (15\%), a configuração de identidades e subjetividades $(14 \%)$ e as atitudes, crenças, valores e percepções sociais $(13 \%)$. O cruzamento das informações relativas à modalidade da Psicologia Social e às temáticas de estudo abordadas permite, porém, uma análise mais pormenorizada dessa questão. Nesse sentido, entre aqueles que se referenciam à perspectiva da Psicologia Social Crítica, os principais temas de estudo são

Tabela 1. Periódicos, fascísculos e artigos avaliados.

\begin{tabular}{lccc}
\hline Periódicos & Período analisado & Número de fascículos & Número de artigos \\
\hline Estudos em Psicologia (Campinas) & $2002-2009$ & 29 & 70 \\
Estudos em Psicologia (Natal) & $1997-2009$ & 34 & 93 \\
Psicologia e Sociedade & $2002-2009$ & 26 & 184 \\
Psicologia em Estudo & $2001-2009$ & 26 & 108 \\
Psicologia: Reflexão e Crítica & $1997-2009$ & 38 & 94 \\
Psicologia: Teoria e Pesquisa & $2000-2009$ & 34 & 87 \\
Total & -------- & 187 & 636 \\
\hline
\end{tabular}

Fonte: Dados da pesquisa 
as práticas sociais, como, por exemplo, a violência, a inclusão e exclusão social, a criatividade etc. (32\%), a configuração de identidades e subjetividades (30\%), as práticas de pesquisa e intervenção em Psicologia Social (15\%) e os papéis de gênero (8\%). Já entre os adeptos da Psicologia Social Psicológica, os temas de maior interesse são as atitudes, crenças, valores e percepções sociais (34\%), as relações interpessoais (17\%), os afetos, emoções e motivação social (16\%) e a autopercepção (12\%). No escopo da Psicologia Social Sociológica, é nítida a preferência pelo tema das representações sociais (91\%), com o percentual restante distribuindo-se entre temas variados.

Vale assinalar que alguns dos artigos classificados nas áreas de atitudes e crenças ou de representações sociais afirmavam estar investigando tais temáticas mas continham apenas uma revisão da literatura associada ao objeto dessas crenças, atitudes ou representações sociais (como, por exemplo, a velhice, a reforma psiquiátrica etc.), sem que houvesse a preocupação de se apresentarem também os fundamentos teóricos subjacentes a essas temáticas. Outros ainda afirmavam estar realizando uma análise psicossocial de algum tema, porém não forneciam maiores evidências sobre a perspectiva teórica que orientava tal análise, o que fez com que por vezes ela tivesse que ser inferida, a partir do tema abordado ou de autores trazidos na discussão dos resultados.

No que diz respeito à metodologia, verificou-se inicialmente se o estudo era de natureza teórica ou empírica. Foram considerados, como artigos teóricos, os estudos caracterizados por revisões críticas de conceitos, modelos e/ou teorias, ou de reflexão e discussão de temas, práticas e métodos de pesquisa e intervenção psicossocial, alicerçados em posições teóricas e por vezes também em casos ilustrativos. Já os artigos empíricos foram classificados como tal se envolvessem procedimentos de coleta e análise de dados.

Os artigos teóricos corresponderam a $34 \%$ da produção total no período analisado, com os demais $67 \%$ referindo-se a estudos empíricos com o uso de metodologias variadas, na qual se sobressai a qualitativa. Cruzando-se essas informações com as vertentes psicossociais, foi possível, porém, observar que, entre os estudos conduzidos na perspectiva da Psicologia Social Crítica, 40\% eram teóricos e 55\% apoiavam-se em estudos empíricos de natureza qualitativa, com os demais adotando outros tipos de metodologias. Já entre os estudos orientados pela Psicologia Social Psicológica, a tendência maior foi pelos estudos quantitativos de natureza correlacional ou comparativa (47\%), seguidos pelos estudos voltados ao desenvolvimento ou adaptação de instrumentos de medida ( $17 \%$ ) e pelos de natureza teórica (11\%), havendo um pequeno número de estudos associados a metodologias experimentais, quantitativo-descritivas ou qualitativas. Por fim, no conjunto de trabalhos alocados na vertente da Psicologia Social Sociológica, constatou-se que a maioria optou pela associação de metodologias qualitativas e quantitativas (56\%) ou pela adoção de metodologias qualitativas (21\%), seguida pelos estudos teóricos (10\%) e com um pequeno número utilizando somente metodologias de cunho quantitativo.

Atendo-se somente aos estudos empíricos, verificou-se que eles vêm utilizando diferentes tipos de amostras, ainda que prevaleçam entre elas os grupos ou indivíduos específicos, como, por exemplo, alcoolistas, pacientes crônicos, usuários de drogas etc. (19\%), estudantes universitários $(18 \%)$, adolescentes $(11 \%)$ ou grupos profissionais, como professores, enfermeiros, trabalhadores em saúde mental etc. $(10 \%)$. Já no que diz respeito aos instrumentos de coleta de dados, a preferência recai nos questionários ou escalas $(50 \%)$, seguidos pelas entrevistas (15\%).

Em síntese, o exame da produção brasileira em Psicologia Social veiculada em seis dos principais periódicos nacionais nos últimos 10 anos permite a conclusão de que as três vertentes atuais da Psicologia Social encontram-se representadas nessa produção, com maior preferência por estudos de natureza teórica ou de natureza empírico-qualitativa conduzidos na perspectiva da Psicologia Social Crítica. Já entre os estudos orientados pela Psicologia Social Psicológica predominam aqueles eminentemente quantitativos e, entre os apoiados na Psicologia Social Sociológica, aqueles de cunho qualititativo-quantitativo. As investigações empíricas associadas às diferentes vertentes têm privilegiado o uso de questionários, escalas ou entrevistas.

Tais resultados apresentam semelhanças e divergências com o levantamento realizado por Ferreira (1992), com base na produção em Psicologia Social veiculada em quatro periódicos (Arquivos Brasileiros de Psicologia Aplicada; Psicologia: Teoria e Pesquisa; Psicologia-USP; PSICO) e nos Anais das Reuniões Anuais da Sociedade de Psicologia de Ribeirão Preto e da Sociedade Brasileira para o Progresso da Ciência, no período de 1980 a 1991. Assim é que, naquela ocasião, a perspectiva da Psicologia Social Psicológica era a dominante e a Psicologia Social Sociológica começava a dar os primeiros passos, não tendo sido detectados indícios de trabalhos que pudessem ser alocados na vertente da Psicologia Social Crítica. Entre os temas mais estudados no período encontravam-se a socialização, a percepção social e as atitudes, crenças e valores. Verifica-se, assim, que o tema das atitudes, crenças e valores, juntamente com a percepção social, vem, há várias décadas, constituindo-se em um dos principais objetos de estudo dos psicólogos brasileiros. Já a temática da socialização não se encontra mais no centro de interesse atual desses investigadores. Por outro lado, a grande diferença entre os dois levantamentos citados diz respeito ao surgimento e consolidação da Psicologia Social Crítica no cenário nacional.

\section{Considerações Finais}

A revisão sobre a evolução e estado atual da Psicologia Social no Brasil e no exterior evidencia que, na América do Norte, a disciplina tem sido dominada pela Psicologia Social Psicológica, de base eminentemente cognitivista e experimental, que se focaliza prioritariamente nos eventos e processos intrapsíquicos que intervêm na relação do indivíduo com seu meio social. Já na Europa, prevalece a Psicologia Social Sociológica, que faz uso de metodologias experimentais e não experimentais, com o intuito de desvendar sobretudo os processos subjacentes às relações que se passam no interior dos grupos sociais e entre grupos. A América Latina, por seu turno, tem aderido cada vez mais à Psicologia Social Crítica, que se preocupa basicamente com os problemas sociais, procurando assim desenvolver um saber autônomo e capaz 
de compreender tais fenômenos. Acompanhando a tendência verificada na América Latina, a Psicologia Social Brasileira tem adotado preferencialmente a Psicologia Social Crítica, muito embora seja possível verificar que as três vertentes atuais da Psicologia Social contemporânea encontram-se representadas na produção brasileira dos últimos 10 anos.

Tais constatações remetem a algumas reflexões acerca das perspectivas futuras dessa produção, no que diz respeito a seu impacto no cenário internacional. Com relação aos artigos de cunho teórico, encontrados, sobretudo, no âmbito da Psicologia Social Crítica, é possível constatar que a maioria tem se limitado a desenvolver reflexões e defender determinados argumentos à luz de autores já consagrados nesse campo de estudos. Poucos e esparsos são, portanto, os trabalhos nos quais se nota a preocupação com a formulação de conceitos, metodologias ou modelos teóricos inovadores, capazes assim de colocar a Psicologia Social Crítica brasileira em posição de destaque no cenário latino-americano ou mesmo norteamericano ou europeu.

Atendo-se aos trabalhos empíricos, verifica-se que há nítida preferência pelas investigações de natureza qualitativodescritiva, que vêm indubitavelmente contribuindo para maior compreensão de uma ampla gama de fenômenos psicossociais, estejam eles referenciados à Psicologia Social Crítica ou à Psicologia Social Sociológica. Seria interessante, porém, que tais estudos pudessem evoluir no sentido de investigar as diferentes alternativas de ação e intervenção propostas, que acabam ficando, na maioria das vezes, apenas no nível de sugestões para estudos futuros. Exemplo disso é o fato de que os trabalhos anteriores de um mesmo autor não são em geral citados em suas publicações subsequentes, em função de cada uma delas se referir a temáticas diferentes. Outrossim, seria preferível que esses estudos adotassem uma linha consistente de invesigação que fosse paulatinamente acumulando informações sobre um objeto de pesquisa ou intervenção de modo a que, ao final de certo tempo, seus autores tivessem condições de reunir um corpo considerável de conhecimentos capazes de exercer algum impacto no cenário nacional e internacional.

Focalizando-se, por fim, nas pesquisas empíricas de natureza quantitativa, utilizadas principalmente na área da Psicologia Social Psicológica, verifica-se que poucas são as de caráter experimental, método preferencial nas publicações internacionais sob essa perspectiva. Nesse sentido, os estudos brasileiros têm optado por recorrer principalmente ao método correlacional ou comparativo, sem, no entanto, lançar mão de ferramentas mais poderosas de análise de dados, como, por exemplo, a modelagem de equações estruturais e outras análises multivariadas, que há alguns anos vêm sendo as estratégias de análise de dados mais adotadas nos estudos internacionais dessa natureza.

Ademais, muitos desses estudos apoiam-se em referenciais frágeis, o que os impede, muitas vezes, de conterem hipóteses sólidas e fundamentadas em evidências teóricoempíricas, característica também marcante nos estudos internacionais. Acrescente-se a isso o fato de que os desenvolvimentos mais atuais no cenário internacional, como a Psicologia Social Evolucionista e a Neurociência Social, têm sido abordados apenas de forma esparsa e, ainda assim, em artigos teóricos. Urge, portanto, que os psicólogos sociais brasileiros adeptos da Psicologia Social Psicológica incorporem os aspectos mencionados em seus futuros trabalhos de investigação, de modo a que eles possam se tornar competitivos no cenário internacional.

Vale ressaltar, ainda, a pouca atenção dada à cultura nos estudos brasileiros em Psicologia Social, independentemente da vertente a que se vinculam. Contudo, a grande diversidade sociocultural que caracteriza o país constitui-se em terreno fértil para a realização de análises sistemáticas e profícuas acerca das características particulares que configuram a identidade, o comportamento e as práticas sociais do brasileiro. Nesse sentido, o desenvolvimento de linhas de pesquisa nessa direção reveste-se indubitavelmente da capacidade potencial de contribuir para a construção de uma verdadeira Psicologia Social brasileira, construída, de forma autônoma, ainda que na interseção da pluralidade de teorias e métodos que configuram a Psicologia Social contemporânea.

À guisa de conclusão, cabe mencionar que o presente trabalho pretendeu realizar uma breve revisão das principais tendências que marcam a Psicologia Social contemporânea, sem pretender, no entanto, ser exaustivo, em função das limitações de espaço e da proposta que o norteou. Nesse sentido, certos recortes e limites precisaram ser efetuados, o que implicou a não abordagem de alguns desdobramentos e temas relevantes à Psicologia Social na atualidade, como, por exemplo, a Psicologia Transcultural, a Etnopsicologia, a Psicologia Institucional etc. Por outro lado, nem todos os periódicos da área de Psicologia foram incluídos no levantamento da produção nacional, nem tampouco as teses e dissertações. Ainda assim, porém, foi possível apontar os consideráveis avanços obtidos pela Psicologia Social nas últimas décadas, no plano internacional e nacional, bem como os desafios que se colocam à produção brasileira da área nesse novo milênio.

\section{Referências}

Aberson, C. L., Healy, M. R., \& Romero, V. L. (2000). Ingroup bias and self-esteem: A meta-analysis. Personality and Social Psychology Review, 4, 157-173.

Abric, J. C. (1994). Pratiques sociales et représentations. Paris: Presses Universitaires de France.

Adolphs, R. (2009). The social brain: Neural basis of social knowledge. Annual Review of Social Psychology, 60, 693-176.

Allport, F. (1924). Social psychology. Boston: Houghton Mifflin.

Allport, G. W. (1954). The historical background of modern social psychology. Em G. Lindzey (Org.), Handbook of social psychology, Vol. 1 (pp. 3-56). Reading: Addison-Wesley.

Álvaro, J. L., \& Garrido, A. (2006). Psicologia social: perspectivas psicológicas e sociológicas. São Paulo: McGraw-Hill.

Apfelbaum, E. (1992). Some teachings from the history of social psychology. Canadian Psychology, 33, 529-539.

Asch, S. (1946). Forming impressions of personality. Journal of Abnormal and Social Psychology, 41, 258-290.

Asch, S. (1952). Social psychology. New York: Prentice Hall.

Bonfim, E.M. (2003). Contribuições para a história da psicologia no Brasil. Em A. M. Jacó-Vilela, M. L. Rocha \& D. Mancebo (Orgs.), Psicologia social: relatos na América Latina (pp. 123-144). São Paulo: Casa do Psicólogo. 
Brown, R. (2000). Social identity theory: Past achievements, current problems and future challenges. European Journal of Social Psychology, 30, 745-778.

Cacioppo, J. T., \& Bernston, G. G. (1992). Social psychological contributions to the decade of the brain: Doctrine of multilevel analysis. American Psychologist, 47, 1019-1028.

Campos, R. H. F., \& Guareschi, P. A. (2000). Paradigmas em psicologia social: A perspectiva Latino-Americana. Petrópolis: Vozes.

Carlston, D. (2010). Social cognition. Em R. F. Baumeister \& E. J. Finkel (Orgs.), Advanced social psychology: The state of the science (pp. 63-100). New York: Oxford University Press.

Carvalho, J. E. C. de, \& Dunker, C. I. L. (2006). Critical psychological approaches in Brazil: When, where, why. Annual Review of Critical Psychology, 5, 305-312. Retirado em 27/07/2010, de www.discourseunit.com/arcp/5.

Chaiken, S., \& Trope, Y. (1999). Dual process theories in social psychology. New York: Guilford.

Crano, W., \& Prislin, R. (2006). Attitudes and persuasion. Annual Review of Social Psychology, 57, 345-374.

Dovidio, J. F., Pearson, A. R., \& Orr, P. (2008). Social psychology and neuroscience: Strange bedfellows or a happy marriage? Group Processes and Intergroup Relations, 11, 249-265.

Fabrigar, L. R. \& Wegener, D. T. (2010). Attitude structure. Em R. F. Baumeister \& E. J. Finkel (Orgs.), Advanced social psychology: The state of the science (pp. 177-216). New York: Oxford University Press.

Fein, S., \& Spencer, S. J. (1997). Prejudice as self-image maintenance: Affirming the self through derogating others. Journal of Personality and Social Psychology, 73, 31-44.

Festinger, L. (1954). A theory of social comparison processes. Human Relations, 7, 117-140.

Festinger, L. (1957). A theory of cognitive dissonance. Stanford: Stanford University Press.

Fiske, S. T., \& Taylor, S. E. (1984). Social cognition. Reading: Addison-Wesley.

Forsyth, D. R., \& Burnette, J. (2010). Group processes. Em R. F. Baumeister \& E. J. Finkel (Orgs.), Advanced social psychology: The state of the science (pp. 495-534). New York: Oxford University Press.

Franzoi, S. L. (2007). History of social psychology. Em R. F. Baumeister \& K. D. Vohs (Orgs.), Encyclopedia of social psychology (pp. 431-439). Thousand Oaks: Sage.

Gergen, K. (1997). Social psychology as social construction. Em C. McGarty \& A. A. Haslam (Orgs.), The message of social psychology (pp. 113-128). London: Blackwell Publishers.

Goethals, G. R. (2003). A century of social psychology: Individuals, ideas and investigations. Em M. A. Hogg \& J. Cooper (Orgs.), The sage handbook of social psychology, Vol. 1 (pp. 3-23). London: Sage.

Grande-García, I. (2009). Neurociencia social: El maridaje entre la psicología social y las neurociencias cognitivas. Revisión e introducción a un nueva disciplina. Anales de Psicología, 25, $1-20$.

Heatherton, T. F., \& Wheatley, T. (2010). Social neuroscience. Em R. F. Baumeister \& E. J. Finkel (Orgs.), Advanced social psychology: The state of the science (pp. 575-612). New York: Oxford University Press.

Heider, F. (1944). Social perception and phenomenal causality. Psychological Review, 51, 358-374.
Heider, F. (1946). Attitudes and cognitive organization. Journal of Psychology, 21, 107-112.

Heider, F. (1958). The psychology of interpersonal relations. New York: John Wiley \& Sons.

Hepburn, A. (2003). An introduction to critical social psychology. Thousand Oaks: Sage.

Hogg, M. A. (2006). Social identity theory. Em P. J. Burke (Org.), Contemporary social psychological theories (pp. 111-136). Palo Alto: Stanford University Press.

Hovland, C. I., Janis, I., \& Kelley, H. (1953). Communication and persuasion. New Haven: Yale University Press.

House, J.S. (1977). The three faces of social psychology. Sociometry, 40, 161-177.

Jacques, M. G. C., Strey, M. N., Bernardes, N. M. G., Guareschi, P. A., Carlos, S. A., \& Fonseca, T. M. G. (1998). Psicologia social contemporânea ( $3^{\mathrm{a}}$ ed.) Petrópolis: Vozes.

Jones, E. E. (1985). History of social psychology. Em G. A. Kimble \& K. Schlesinger (Orgs.), Topics in the history of psychology, Vol. 2 (pp. 371-407). Hillsdale: Lawrence Erlbaum Associates.

Jones, E. E., \& Davis, K. E. (1965). From acts to dispositions: The attribution process in person perception. Em L. Berkowitz (Org.), Advances in experimental social psychology, Vol. 2 (pp. 219-226). New York: Academic Press.

Kelley, H. (1967). Attribution theory in social psychology. Em D. Levine (Org.), Nebraska symposium on motivation (pp. 192-238). Nebraska: University of Nebraska Press.

Lane, S., \& Codo, W. (1984). Psicologia social: o homem em movimento. São Paulo: Brasiliense.

Lane, S., \& Sawaia, B. (1994). Novas veredas da psicologia social. São Paulo: Brasiliense.

Lewin, K., Lippitt, R., \& White, R. K. (1939). Patterns of aggressive behavior in experimentally created "social climates". Journal of Social Psychology, 10, 271-299.

Mancebo, D., \& Jacó-Vilela, A. M. (2004). Psicologia social: abordagens sócio-históricas e desafios contemporâneos. Rio de Janeiro: EDUERJ.

Maner, J. K., \& Kenrick, D. T. (2010). Evolutionary social psychology. Em R. F. Baumeister \& E. J. Finkel (Orgs.), Advanced social psychology: The state of the science (pp. 613-653). New York: Oxford University Press.

Martin-Baró, I. (1989). Sistema, grupo y poder: Psicologia social desde Centroamérica. San Salvador: UCA.

Martin-Baró, I. (1996). O papel do psicólogo. Estudos de Psicologia, 2, 7-27.

McGarty, C., \& Haslam, S.A. (1997). Introduction and a short history of social psychology. Em C. McGarty \& A. A. Haslam (Orgs.), The message of social psychology (pp. 1-19). London: Blackwell Publishers.

McDougall, W. (1908). Introduction to social psychology. London: Methuen.

McGuire, W. J. (1968). The nature of attitudes and attitude change. Em G. Lindzey \& E. Aronson (Orgs.), Handbook of social psychology, Vol. 3 (2 ${ }^{\mathrm{a}} \mathrm{ed}$ ) (pp. 136-314). Reading: AddisonWesley.

Mesoudi, A. (2009). How cultural evolutionary theory can inform social psychology and vice versa. Psychological Review, 116, 929-952.

Milgram, S. (1965). Liberating effects of group pressure. Journal of Personality and Social Psychology, 1, 127-134. 
Molina-Valencia, N., \& Mesa, A. M. E. (2006). Critical construction of psychology in Colombia. Annual Review of Critical Psychology, 5, 342-353. Retirado em 22/07/2010, de www. discourseunit.com/arcp/5.

Montero, M., \& Montenegro, M. (2006). Critical psychology in Venezuela. Annual Review of Critical Psychology, 5, 257-268. Retirado em 22/07/2010, de www.discourseunit.com/arcp/5.

Moura, G. R., Leader, T., Pelletier, J., \& Abrams, D. (2009). Prospects for group processes and intergroup relations research: A review of 70 years' progress. Group Processes and Intergroup Relations, 11, 575-596.

Moscovici, S. (1978). A representação social da psicanálise (A. Cabral, Trad.). Rio de Janeiro: Zahar. (Trabalho original publicado em 1961)

Moscovici, S. A. (1981). On social representations. Em J. P. Forgas (Org.), Social cognition: Perspectives on everyday understanding (pp. 189-201). London: Academic Press.

Moscovici, S. (1984). The phenomenon of social representations. Em R. M. Farr \& S. Moscovici (Orgs.), Social representations (pp. 3-69). Cambridge: Cambridge University Press.

Overwalle, F. V. (2009). Social cognition and the brain: A metaanalysis. Human Brain Mapping, 30, 829-858.

Pennington, D. C. (2000). Social cognition. London: Routledge. Pepitone, A. (1981). Lessons from the history of social psychology. American Psychologist, 36, 972-985.

Petty, R. E., \& Briñol, P. (2010). Attitude change. Em R. F. Baumeister \& E. J. Finkel (Orgs.), Advanced social psychology: The state of the science (pp.217-259). New York: Oxford University Press.

Potter, J., \& Wetherell, M. (1987). Discourse and social psychology: Beyond attitudes and behavior. London: Sage.

Quinn, K. A., Macrae, C. N., \& Bodenhausen, G. V. (2003). Social cognition. Em L. Nadel (Org.), Encyclopedia of cognitive science, Vol. 4 (pp. 66-73). London: Macmillan.

Rodrigues, A., Assmar, E. M. L., \& Jablonski, B. (2000). Psicologia social (18 ${ }^{\mathrm{a}}$ ed. ref.). Petrópolis: Vozes.

Ross, E. A. (1908). Social psychology. New York: Macmillan.

Ross, L. (1977). The intuitive psychologist and his shortcoming: Distortions in the attribution process. Em L. Berkowitz (Org.), Advances in experimental social psychology, Vol. 10 (pp. 173-220). New York: Academic Press.
Ross, L., Lepper, M., \& Ward, A. (2010). History of social psychology: Insights, challenges and contributions to theory and application. Em S. T. Fiske, D. T. Gilbert \& G. Lindzey (Orgs.), The handbook of social psychology $\left(5^{\text {th }}\right.$ ed.) (pp. 3-50). NewYork: Wiley.

Sá, C. (1996). Núcleo central das representações sociais. Petrópolis: Vozes.

Saucier, G. (2000). Isms and the structure of social attitudes. Journal of Personality and Social Psychology, 78, 366-385.

Schwarz, N. (1998). Warmer and more social: Recent developments in cognitive social psychology. Annual Review of Sociology, 24, 239-264.

Shafir, I. P. (2006). Reflections on the emergence of a critical psychology in Chile. Annual Review of Critical Psychology, 5, 269-280. Retirado em 27/07/2010, de www.discourseunit.com/ $\operatorname{arcp} / 5$.

Sheriff, M. (1936). The psychology of social norms. New York: Harper.

Smith, E. R., \& Collins, E. C. (2009). Contextualizing person perception: Distributed social cognition. Psychological Review, 116, 343-364.

Spink, M. J., \& Spink, P. (2005). A psicologia social na atualidade. Em A. M. Jacó-Vilela, A. A. L. Ferreira \& F. T. Portugal (Orgs.), História da psicologia: Rumos e percursos (pp. 565-585). Rio de Janeiro: Nau.

Stephan, C. W., \& Stephan, W. G. (1985). Two social psychologies: An integrative approach. Homewood: Dorsey.

Tajfel, H. (1981). Human groups and social categories: Studies in social psychology. Cambridge: Cambridge University Press.

Tajfel, H., \& Turner, J. C. (1986). The social identity theory of intergroup behavior. Em S. \& Worchel \& W. Austin (Orgs.), The social psychology of intergroup relations. Chicago: Nelson Hall.

Turner, J. C., Hogg, M. A., Oakes, P. J., Reicher, S. D., \& Wetherell, M. S. (1987). Rediscovering the social group: A selfcategorization theory. Oxford: Basil Blackwell.

Weiner, B. (1986). An attributional theory of motivation and emotion. New York: Springer-Verlag. 